\title{
268 KVA 12.1 A NOVEL FULLY HUMAN ANTI-VISTA ANTIBODY: CLINICAL TRIAL DESIGN IN MONOTHERAPY AND IN COMBINATION WITH AN ANTI-PD1 ANTIBODY
}

Thierry Guillaudeux*, Shawn Iadonato, Eric Tarcha, Craig Philips. Kineta Inc., Seattle, WA, USA

Background V-domain Ig Suppressor of $\mathrm{T}$ cell Activation (VISTA) is an immune-suppressive checkpoint inhibitor of $\mathrm{T}$ cell response. VISTA is expressed in the immuno-suppressive tumor microenvironment, mostly by cells of the myeloid lineage, and its blockade can restore an efficient antitumor immune response especially in hard-to-treat tumors. ${ }^{1}$ In addition, an increase in VISTA expression has been described after treatment by the current immune checkpoint inhibitors, antiCTLA-4 or anti-PD1-(L), ${ }^{1}$ especially in patients refractory to these treatments. ${ }^{2} 3$ Therefore, VISTA may be involved in a compensatory resistance mechanism to checkpoint inhibitors.

Methods Kineta has selected a lead candidate anti-VISTA monoclonal antibody, KVA12.1, after a deep screen of 107 fully human and highly diverse antibodies directed against the extracellular domain of VISTA.

Results KVA12.1 exhibits high potency and binds to a unique epitope. It restores $\mathrm{T}$ cell activation and induces a pro-inflammatory response in in vitro assays. In vivo, in human VISTA knock-in mice, KVA12.1 treatment mediates strong singleagent antitumor activity in multiple syngeneic tumor models and shows enhanced efficacy in combination with either antiPD-(L)1 or anti-CTLA-4 treatment. Finally, our anti-VISTA antibody was well-tolerated in exploratory toxicology studies in cynomolgus monkey, where hematology and clinical chemistry evaluations as well as clinical observations including monitoring of body weight revealed no indicators of toxicity. Safety endpoints, including the monitoring of cytokine levels related to cytokine release syndrome (CRS), clinical pathology and immunogenicity were evaluated. Cytokine levels associated with CRS (e.g., TNF-alpha, IL-6, IL-1 $\beta$ ) were assessed, and none were elevated to levels associated with CRS. These studies provided drug exposures (AUC) well over the expected exposures required for clinical efficacy, and KVA12.1 exhibits a good half-life consistent with other monoclonal check-point inhibitors. We are currently engaged in pre-IND studies and manufacturing of KVA12.1.

Conclusions Here we are presenting the design of a phase 1/2 multicenter, open label, dose escalation and dose expansion study of intravenous infusion of KVA12.1 as a monotherapy and in combination with a fixed dose of an anti-PD1 antibody in patients with advanced refractory or metastatic solid tumors.

\section{REFERENCES}

1. ElTanbouly MA, Schaafsma $E$, Noelle RJ, Lines JL. VISTA: Coming of age as a multi-lineage immune checkpoint. Clin Exp Immunol 2020;200(2):120-130.

2. Kuklinski LF, Yan S, Li Z, Fisher JL, Cheng C, Noelle RJ, Angeles CV, Turk MJ, Ernstoff MS. VISTA expression on tumor-infiltrating inflammatory cells in primary cutaneous melanoma correlates with poor disease-specific survival. Cancer Immunol Immunother 2018 July:67(7):1113-1121.

3. Kakavand H, Jackett LA, Menzies AM, Gide TN, Carlino MS, Saw RPM, Thompson JF, Wilmott JS, Long GV, Scolyer RA. Negative immune checkpoint regulation by VISTA: a mechanism of acquired resistance to anti-PD-1 therapy in metastatic melanoma patients. Mod Pathol 2017 December;30(12):1666-1676.

http://dx.doi.org/10.1136/jitc-2021-SITC2021.268 